\title{
INFLUENCIADORES DA PERCEPÇÃO DE EFICÁCIA DO BOICOTE E INTENÇÃO DE BOICOTAR
}

\author{
ANTECEDENTS OF PERCEPTION OF BOYCOTT EFFECTIVENESS \\ AND INTENTION TO BOYCOTT
}

\author{
Recebido em 05.09.2016. Aprovado em 16.11.2016 \\ Avaliado pelo sistema double blind review \\ DOI: http://dx.doi.org/10.12712/rpca.v10i4.763
}

\section{Breno de Paula Andrade Cruz \\ brenocruz@ufrrj.br \\ Universidade Federal Rural do Rio de Janeiro (UFRRJ), Seropédica/RJ, BRASIL}

\section{Delane Botelho}

delane.botelho@fgv.br

Fundação Getulio Vargas - EAESP (FGV), São Paulo/SP, BRASIL

\section{Resumo}

Este artigo investiga, por meio de um experimento, o efeito das variáveis Responsabilidade Social Corporativa (RSC), Gênero e Tipo de Bem na Percepção de Eficácia do Boicote (PEB) e Intenção de Boicotar (IB). Os resultados evidenciam que quanto menor a percepção de RSC do consumidor em relação a uma empresa, maior é a sua PEB e IB - ou seja, respectivamente, o consumidor percebe individualmente que o seu boicote é uma ação importante para que a empresa mude seu comportamento; e ele tem intenção de boicotar quando a empresa parece não ter uma orientação para RSC. Embora estudos evidenciem que mulheres estejam mais propensas a boicotar que homens, não houve nesta amostra diferença de gênero em relação a PEB e IB. Verificou-se que PEB e IB são menores para um bem de luxo quando comparado a um bem essencial. Ou seja, as características de um bem de luxo podem levar o consumidor a um conflito interno em relação ao boicote pelo fato do bem de luxo apresentar características peculiares que os tornam singulares, e portanto, os tornam menos vulnerável ao boicote. Implicações teóricas e gerenciais são destacadas à destaa literatura de comportamento do consumidor.

Palavras-chave: Intenção de Boicotar. Percepção de Eficácia do Boicote. Bem de Luxo. Responsabilidade Social Corporativa. Gênero.

\begin{abstract}
This article investigates, through an experiment, the effect of the variables Corporate Social Responsibility (CSR), Gender and Type of Good in the Perception of Boycott Effectiveness (PEB) and Boycott Intention (IB). The results show that the lower the CSR perception of the consumer in relation to a company, the greater its $\mathrm{PEB}$ and IB, - that is, the consumer individually perceives that boycott is an important action for the company to change its behavior; and she/he intends to boycott when the company does not seem to have a CSR orientation. Although studies have shown that women are more likely to boycott than men, there was no gender difference in PEB and IB in our sample. We found that PEB and IB are lower for a luxury/exclusive good when compared to an essential good. That is, the characteristics of luxury goods can lead the consumer to an internal conflict over the boycott since such products have peculiar characteristics that make them unique, and therefore, make them less vulnerable to boycotts. Theoretical and managerial implications are discussed in light of consumer behavior literature.
\end{abstract}

Keywords: Intention to Boycott. Perception of Boycott Effectiveness. Luxury Goods. Corporate Social Responsibility. Gender. 


\section{Introdução}

Transformações na percepção do consumidor sobre a atuação das empresas revelam um fenômeno que poderia ser melhor investigado em Marketing: o boicote do consumidor. Embora o tema tenha sido incorporado à discussão do comportamento do consumidor nos últimos anos, ele foi usado pela primeira vez por volta de 1880, para designar uma retaliação organizada por pequenos comerciantes que negociavam com um grande fazendeiro americano, senhor Charles Boycott. A partir do momento que o grupo de pequenos comerciantes percebeu que poderia fazer uma retaliação ao fazendeiro deixando de comprar seus produtos mediantes suas exigências descabidas, usou-se pela primeira vez o termo boycott (SOULE, 2009).

No Brasil há evidências de boicote tanto no ambiente virtual quanto no real, tais como: i) a empresa brasileira Arezzo que utilizou em sua coleção pele de animais (SOARES, 2011); ii) a novela Salve Jorge da Rede Globo que sofreu boicote de telespectadores evangélicos pelo fato de abordar explicitamente um santo católico em seu enredo (GOES, 2012; CRUZ, 2016a); iii) a empresa multinacional Zara que esteve envolvida no Brasil num escândalo de mão-de-obra semi-escrava em sua cadeia de suprimentos (PYL; HASHIZUME, 2011); e as experiências negativas do consumidor no relacionamento frustrado com uma empresa influenciando o boicote (CRUZ; BOTELHO, 2015).

As motivações para o boicote podem ser de várias naturezas e variam de acordo com suas dimensões econômica, ideológica e experencial. $\mathrm{Na}$ dimensão econômica, os consumidores podem boicotar uma empresa por questões como estrutura de mercado (por exemplo, monopolista), percepção de preços abusivos ou pela ausência de produtos substitutos diretos, que designam o boicote econômico. Já na dimensão ideológica, o boicote também pode ocorrer em função de negligência de uma empresa ao meio ambiente ou maus tratos a animais (boicote ecológico); em virtude de posicionamentos religiosos ou espirituais (boicote religioso); em represália a comentários ou posicionamentos contrários a grupos marginalizados na sociedade (boicote de minorias); ou em resposta a questões relacionadas ao trabalho e aos direitos humanos (labor boycott). Na dimensão experiencial, o boicote motivado pela experiência negativa do consumidor com uma empresa foi classificado como boicote relacional (CRUZ; BOTELHO, 2015).
Este artigo investiga, por meio de um experimento, o efeito das variáveis Responsabilidade Social Corporativa (RSC), Gênero e Tipo de Bem na Percepção de Eficácia do Boicote (PEB) e Intenção de Boicotar (IB). A discussão sobre Responsabilidade Social Corporativa (RSC) e seus desdobramentos pode influenciar o consumidor em sua decisão de boicotar, pois, nesse caso, as motivações para o boicote podem estar relacionadas às variáveis psicossociais (valores ideológicos, gênero, culpa e influência de terceiros) conforme direcionam os estudos de Soule (2009), Klein Smith e John (2004), Friedman (1999) e Koku (2011). É possível que o gênero seja também seja uma variável influenciadora na propensão a boicotar (KLEIN; SMITH; JOHN, 2004), uma vez que em alguns estudos estrangeiros observou-se que a mulher tende a boicotar mais que os homens (NEILSON, 2010; STOLLE; HOGGE; MICHELETTT, 2005), por características que podem ir desde questões históricas do papel da mulher na sociedade (indivíduo que cuida da família) a questões intrínsecas e psicológicas (conflitos emocionais). Outro aspecto relevante em estudos de boicote é o conflito emocional interno que o consumidor tem ao decidir em boicotar um produto, serviço ou marca (KOZINETS; HANDELMAN'S, 1998), gerando o que Sen, Gürhn e Morwitz (2001) conceituam como Custo do Boicote, que faz emergir o questionamento sobre a relação entre o tipo de bem (essencial ou de luxo) e o boicote do consumidor. Talvez exista um conflito emocional interno maior do consumidor em relação ao boicote de bens de luxo, que possuem características singulares, como a raridade e o status que a compra e o uso trazem ao seu consumidor, fazendo com que o custo do boicote aumente, em comparação a um bem essencial.

O artigo está assim estruturado: esta seção introduziu o tema e o objetivo do trabalho. A segunda seção apresenta o referencial teórico e as hipóteses da pesquisa, seguida pelo método, com o desenho do experimento e os procedimentos de coleta e análise dos dados. O artigo é finalizado com as principais conclusões, implicações e sugestões de pesquisa futura sob o enfoque do campo de estudo do comportamento do consumidor.

\section{Boicote do consumidor}

Boicote é o ato de o consumidor deixar de comprar um produto ou serviço de uma empresa pelo fato de ele não concordar com situações pontuais ou 
corriqueiras adotadas por uma empresa na interação direta ou indireta com seu público interno ou externo, indo contra seus valores ideológicos ou econômicos (FRIEDMAN, 1999; KLEIN; SMITH; JOHN, 2004; SOULE, 2009).

Aqui distingue-se boicote de backlash, sendo este último qualquer tipo de manifestação de repúdio do consumidor ou da sociedade em relação à atuação de uma empresa (KLEIN; SMITH; JOHN, 2004).. A situação em que os valores pessoais do consumidor não correspondem aos valores organizacionais de uma empresa e que gera um comportamento de repúdio deste com relação, por exemplo, às práticas de RSC, resultando em possíveis prejuízos tangíveis e intangíveis a uma marca, é chamado de backlash (SMITH; PALAZZO; BHATTACHARYA, 2010, p. 622). Um tipo de backlash é o anticonsumismo, que é uma forma de rejeição de uma marca, empresa ou produto, relacionada a questões políticas, ideológicas ou econômicas, envolvendo sempre um grupo de ativistas por meio de uma postura mais proativa na discussão da atuação de uma empresa (VARMAN; BELK, 2009).

O receio do boicote pelas empresas é explicado a partir de casos de grandes marcas, como Nike, Coca Cola e Shell. No caso da Nike, que envolveu o escândalo da utilização de mão-de-obra infantil na China em sua cadeia de suprimentos, o boicote e manifestações de backlash dos consumidores, com apoio de uma Organização Não Governamental (ONG), fez com que o presidente da empresa recebesse mais de 33 mil cartas solicitando mudanças nas condições de trabalho na cadeia de suprimentos da empresa (PALAZZO; BASU, 2007). Este exemplo evidencia que a decisão de consumo pode afetar as práticas laborais (SMITH; PALAZZO; BHATTACHARYA, 2010) de uma empresa ou de sua cadeia de suprimentos, pois a Nike teve que rever suas parcerias externas e suas condições internas de atuação. No Brasil, manifestações de consumidores e ativistas nas redes sociais virtuais (RSVs) têm se mostrado a principal prática de backlash como forma de influenciar algumas empresas a mudarem seus comportamentos relacionados à sociedade, ao meio ambiente, às minorias e à religião (CRUZ, 2016a).

Por pressão de boicote de universidades americanas e canadenses, a Coca Cola teve que rever sua atuação na Colômbia por causa de violação de direitos humanos. Essa revisão da empresa se deu em função do cancelamento de contratos e produtos da Coca Cola em 20 universidades naqueles dois países. Já a Shell perdeu entre 10 e 15 milhões de dólares por dia no ano de 1999 pelo fato dos consumidores terem boicotado a empresa pelo caso Brent Spar, uma instalação de reserva de petróleo retirada de utilização em 1991. Em 1995 a empresa anunciou o afundamento do equipamento a 2,5km de profundidade no oceano Atlântico, o que gerou protestos de organizações, como a ONG Green Peace, e consumidores. O Green Peace apurou também que a Shell perdeu 7\% de participação de mercado logo após decidir não aderir ao Protocolo de Kyoto (AAKER, 2004).

Em contexto brasileiro, os casos de boicote não são recentes e relatos envolvendo backlash e boicote são encontrados em fontes jornalísticas desde a década de 1990. Um dos primeiros eventos relatados na imprensa brasileira foi o caso envolvendo a empresa Parmalat, o Palmeiras Futebol Clube e a Portuguesa Futebol Clube (ambos times do estado de São Paulo). Na década de 1990 um jogador palmeirense pisou na camisa da Portuguesa ao final de um jogo. Como a Parmalat era a empresa patrocinadora do Palmeiras, consumidores que não simpatizaram com a atitude do jogador deixaram de comprar produtos da empresa. Durante duas semanas a perda da Parmalat foi de R $\$$ 100.000,00, o equivalente em 2016 a $\mathrm{R} \$ 500.000,00$ (BLOG DA PORTUGUESA, 2011).

Em outro contexto, na Administração Pública, em 2008, moradores da cidade do Rio de Janeiro se organizaram juntamente com sete associações de bairros da cidade para reivindicarem junto à prefeitura municipal melhorias nas vias públicas, segurança pública, diminuição da favelização urbana e a retirada de lombadas eletrônicas ligadas 24 horas que aumentam as chances de assaltos. Os consumidores dos serviços públicos resolveram pagar em juízo o IPTU da cidade, uma maneira de boicotar a principal receita do município. $\mathrm{Na}$ percepção dos consumidores/cidadãos, pagar em juízo faria com que a prefeitura trabalhasse em prol das melhorias, uma vez que o prejuízo estimado fora de $\mathrm{R} \$ 7,4$ milhões.

Alunos de uma tradicional escola do ensino médio na cidade de São Paulo evidenciaram como um boicote pontual poderia ganhar notoriedade no país por meio das RSVs - especificamente pelo Twitter. Em 2011, alunos manifestaram no Twitter (backlash) e deixaram de comprar (boicote) seus lanches na cantina do colégio porque o preço do pão de queijo teve um aumento de $15 \%$. Os alunos filmaram o protesto, disponibilizaram o vídeo no Twitter e em menos de 
24 horas era o assunto mais comentado da internet brasileira (G1, 2011).

Embora os jovens do início do século XXI pareçam ser mais críticos quando comparados às gerações anteriores, no que diz respeito à intenção de compra em relação a comportamentos ambientais e sociais das empresas, não se percebeu muita mudança nas atitudes em relação às gerações passadas. Um estudo conduzido pelo Centro de Altos Estudos da Escola Superior de Propaganda e Marketing (CAEPM, 2010), nas cidades do Rio de Janeiro e São Paulo, verificou que o brasileiro entre 16 e 25 anos concorda que pode influenciar as ações das empresas, mas ainda não consome com um viés político significativo. Neste caso, consumir politicamente implica na avaliação dos consumidores sobre as práticas das empresas no que tange seus comportamentos éticos, tanto na perspectiva ambiental quanto social (BARBOSA, 2010), o que pode impactar na intenção ou decisão de boicote.

A lacuna de credibilidade existente entre a comunicação de marketing relacionada às ações de RSC e os reais problemas ambientais e sociais que uma empresa está inserida, evidencia o problema da percepção do consumidor com relação à atuação daquela empresa, o que pode influenciar sua decisão no momento da compra ou na participação em um boicote (PALAZZO; RICHTER, 2005). Entender e gerenciar situações que envolvam membros da cadeia de suprimentos (principalmente as empresas terceirizadas) pode ser importante na construção da orientação gerencial para RSC. Por exemplo, empresas como Nike e Apple tiveram que se retratar diante da sociedade, investidores e consumidores sobre a utilização de trabalho semiescravo ou infantil na China no início da década de 2000. Embora sejam atores indiretos, estes stakeholders acabam por influenciar a gestão de RSC em uma empresa, e a falta de transparência e corrupção (direta ou indireta) são fatores que influenciam uma orientação socialmente responsável.

Em outra perspectiva, na dimensão econômica, o boicote tem forte relação com a renda e com o aumento de preços. Na Grécia, Barda e Sardianou (2010) evidenciaram que mais de $50 \%$ dos consumidores boicotaram produtos alimentícios após o aumento de preços no momento da crise financeira do país. Em reflexo ao boicote, os autores verificaram que produtos alimentícios foram os mais afetados, uma vez que $49 \%$ dos respondentes informaram que são favoráveis ao boicote para evitar a formação de cartel. Outro influenciador do boicote é o tipo de mercado. Na perspectiva do vendedor, é usual que algumas empresas queiram atuar em um mercado monopolista ou com poucos concorrentes. Já na percepção dos consumidores, eles estarão mais satisfeitos se estiverem em um mercado competitivo e com diversas possibilidades de escolhas (BAKER, 2005). Quando uma empresa atua na situação de monopólio é pouco provável que ela utilize os preços como dados para precificar um produto ou serviço, o que coloca o consumidor em uma posição passiva (ENGLE-WARNICK; RUFLLE, 2002). Ao contrário do mercado perfeito, que se caracteriza pela existência de grande número de compradores e vendedores, diversificação de pequenos e grandes fornecedores, e fixação de preços baseada, além dos custos, nas informações de mercado e na concorrência (KREEPS, 2004), o mercado monopolista se caracteriza pela presença de somente um vendedor e, consequentemente, este terá um poder monopolista ao afetar o mercado por meio de suas ações e decisões de preço (LANDSBURG, 2002).

Como exemplo de boicote na atuação monopolista no Brasil, o Ministério Público do Rio Grande do Norte e os PROCONs do estado lançaram uma campanha em abril de 2011 para que os consumidores não comprassem combustível nos Postos BR, uma vez que foram abusivos os preços cobrados pela BR Distribuidora (MOURA; MENDES, 2011). Entretanto, a eficácia da ação foi questionada, uma vez que a necessidade de se ter o combustível pode fazer com que o consumidor não leve em consideração as práticas abusivas de preço (mesmo que alertados por órgãos como o Ministério Público e PROCON). Assim, o grau de importância do produto para o consumidor pode ser um driver motivador para o boicote. Embora questionada a eficácia do boicote no Rio Grande do Norte, os desdobramentos desta ação coletiva geraram não somente perdas financeiras, mas também problemas gerenciais para alguns postos de gasolina. Um grupo de usuários de uma rede social virtual (Orkut) criou uma comunidade em que os participantes pudessem debater o aumento do preço da gasolina e derivados (MOURA; MENDES, 2011). $O$ protesto deixou o atendimento bem lento nos postos, uma vez que os clientes colocavam centavos de gasolina (entre $\mathrm{R} \$ 0,10$ e $\mathrm{R} \$ 1,00$ ) e, algumas vezes, pediram valores não inteiros para dificultar a devolução do troco em moedas para atrasar o atendimento. A redução do consumo foi de aproximadamente 35\% em relação aos meses anteriores. 
Alguns artigos na literatura internacional de marketing investigaram os drivers motivadores do boicote. Klein, Smith e Jonh (2004) verificaram: (i) a propensão de boicotar e o gênero: mulheres estão mais dispostas a boicotar que os homens; (ii) pessoas que acreditam fazer a diferença estarão mais propensas a boicotar se outros já boicotaram; e (iii) pessoas que usam contra argumentos para não boicotar, como corte de empregos dos funcionários daquela empresa, não boicotarão se sabem se outros já boicotaram. Barda e Sardianou (2010), por meio de um estudo empírico com 200 consumidores na Grécia, concluíram que as mulheres estão mais propensas a participar de boicotes do que os homens, e existe uma relação entre menor idade e propensão em boicotar. Os resultados sugerem que os gregos até os 32 anos de idade, em média, estão mais propensos a boicotar, uma vez que $\mathrm{o}$ interesse pelo boicote diminuiu na amostra analisada a partir dos 33 anos de idade.

\section{Hipóteses do estudo}

A seguir são desenvolvidas as seis hipóteses da presente pesquisa:

$\mathrm{O}$ ato de deixar de comprar um produto ou serviço de uma empresa como forma de manifestação pode ser concebido pelo boicotador levando em consideração diversos atributos, conforme os tipos de boicote apresentados anteriormente neste estudo. Atributos relacionados à RSC influenciam consumidores a deixarem de comprar produtos de uma empresa que não possui uma conduta condizente àquela esperada por eles (AAKER, 2004; SMITH; PALAZZO; BHATTACHARYA， 2010; FRIEDMAN， 1999; SOULE, 2009; NAN; HEO, 2007). Em outras palavras, pode haver um choque entre percepção de atuação da empresa e os valores do consumidor, em relação à RSC .

Alguns movimentos anticonsumo evidenciam como os boicotes, em muitos casos, estão relacionados à RSC. Por exemplo, em 1992 a Time Warner sofreu um boicote organizado pela Law Enforcement Association of Texas para que a música 'Cop Killer' do rap Ice-T fosse retirada do álbum (GELB, 1995). Enquanto o músico defendia a licença poética, a venda do $\mathrm{CD}$ foi proibida no estado do Alabama, e voluntariamente em outros estados empresas suspenderam as vendas. No Brasil, por exemplo, consumidores têm se engajado, em diferentes aspectos, às causas relacionadas à RSC, como o caso de consumidoras que criticaram a marca de roupas de luxo Maria Filó por uma brincadeira com uma funcionária grávida, e repudiarem a marca e explicitaram seu boicote nas RSVs (CRUZ; PIRESJR; ROSS, 2016).

O desrespeito à cultura e à religião já foi verificado em casos no Bahrein e no Brasil, respectivamente, e reflete a percepção de necessidade de respeito da empresa com os valores e credos dos membros de uma determinada sociedade. No Bahrein, uma indústria de laticínios foi obrigada a trocar o nome depois de ver suas vendas caírem 35\% como uma resposta a desenhos desrespeitosos aos muçulmanos (DAIRY INDUSTRIES, 2006). No Brasil, um primeiro caso de boicote religioso encontrado na literatura evidencia a pressão de instituições religiosas no boicote. A marca de lingerie Du Loren sofreu uma retaliação da igreja católica pelo fato de uma das suas propagandas apresentarem uma mulher com roupas íntimas, na Praça São Pedro no Vaticano, criticando a violência sexual de padres com crianças e adolescentes. O resultado da retaliação da Igreja Católica no Brasil foi expor aos seus fiéis em todo o país que a propaganda era satânica, fazendo com que a marca perdesse a liderança na participação de mercado de lingerie no Brasil (GASTALDO, 2004). Posteriormente, alguns outros casos relacionados ao boicote religioso já foram analisados na literatura como a tentativa da Frente Parlamentar Evangélica composta por deputados federais influenciarem seus seguidores a deixarem de comprar da empresa de cosméticos Natura pelo fato de ela patrocinar a novela Babilônia da Rede Globo que apresentava temas relacionadas à causa LGBTS (CRUZ; ROSS, 2016).

A Nike, como relatado anteriormente, exemplifica a força de um boicote pelo fato dos consumidores não concordarem com o trabalho infantil utilizado por empresas terceirizadas contratadas na China, e demonstra a relação da percepção de RSC do consumidor e sua atitude de boicote (PALAZZO; BASU, 2007). Outros estudos como Nan e Heo (2007) e Matilla et al. (2010) buscaram entender o impacto da RSC no boicote. Klein, Smith e Jhon (2004) apresentaram uma escala para mensurar a motivação dos consumidores para o boicote, sendo que uma das dimensões foi a Percepção de Eficácia do Boicote (PEB). Cruz, Pires-Jr e Ross (2013) validaram tal escala em contexto brasileiro para analisarem tal dimensão. Assim, é possível que a orientação gerencial para RSC de uma empresa interfira na Percepção de Eficácia do 
Boicote (PEB) pelo do consumidor, definida como a percepção do consumidor sobre o boicote como uma estratégia individual para que uma empresa mude suas ações, decisões e estratégias de atuação (Klein, Smith e Jhon, 2004). Uma alta PEB significa que o consumidor acredita que o boicote será eficaz para que a empresa mude sua atuação. O estudo de Cruz et al. (2013) explorou teoricamente a possibilidade da falta de orientação para responsabilidade social corporativa poder influenciar a intenção de boicote pelos consumidores. Entretanto, nenhuma proposição foi testada em termos de modelo conceitual ou a análise de dados empíricos. Então, tem-se $\mathrm{H}_{1}$

\section{$\mathrm{H}_{1}$ : Quanto menor a percepção de Responsabilidade Social Corporativa (RSC) do consumidor sobre uma empresa, maior a sua Percepção de Eficácia do Boicote (PEB).}

As atitudes e intenções do consumidor podem ou não estar relacionados com seu comportamento de boicote no que diz respeito à atuação socialmente responsável da empresa, mas o consumidor pode considerar como importante o fato da empresa ter que mudar as ações e decisões com relação à RSC, mas não necessariamente deixará de comprar da empresa.

$\mathrm{H}_{2}$ : Quanto menor a percepção de Responsabilidade Social Corporativa (RSC) do consumidor sobre uma empresa, maior a sua Intenção de Boicotar (IB) tal empresa.

Alguns pesquisadores estrangeiros observaram que o gênero do consumidor pode influenciar o boicote. Como apresentado anteriormente, Barda e Sardianou (2010), ao analisarem o comportamento do consumidor grego no momento da crise financeira do país e a intenção deles em boicotar, verificaram que as mulheres, proporcionalmente, boicotavam mais que os homens. Levando em consideração o ramo de atuação da empresa em que o levantamento foi conduzido (supermercados), talvez essa maior inclinação da mulher ao boicote fosse explicada pela sua maior freqüência de compra em relação aos homens neste mercado. Entretanto, os autores controlaram essa variável para que o efeito freqüência não gerasse um viés nos resultados. Mesmo assim, mulheres se mostraram mais propensas ao boicote que os homens.

Alguns estudos apontam maior predisposição das mulheres em relação aos homens em consumir politicamente (NEILSON, 2010; STOLLE; HOGGE; MICHELETTTI, 2005), pressupondo aqui que o boicote seja uma forma de consumo político. Em Neilson (2010), as mulheres apresentaram um comportamento favorável ao boicote aproximadamente 10\% superior em relação aos homens. Levantamentos realizados na Suécia, Canadá e Bélgica apontaram que a mulher está mais propensa em boicotar que o homem em 16\% (STOLLE; HOGGE; MICHELETTI, 2005) dos casos, mesmo controlando pelo fato que as mulheres vão mais aos shoppings ou realizam mais compras de alimentos que os homens. Klein, Smith e John (2004) também observaram que mulheres estão mais predispostas que os homens neste tipo de ação: o fato da mulher tradicionalmente ter maior preocupação e um comportamento mais cuidadoso com a família faz com que ela esteja mais predisposta a boicotar (como forma de consumo político) pelo fato de que analisam situações ou circunstâncias complexas de maneira mais aprofundada, quando comparadas aos homens.

Uma evidência empírica da organização e predisposição das mulheres ao boicote e que teve repercussão nos Estados Unidos em 2010 e 2011 foi a decisão de boicotar produtos de empresas que impactam a saúde das consumidoras (KALSEN, 2005). O grupo Girlcott (junção das palavras girl e boycott) traduz a importância da mulher neste tipo de decisão e engajamento político em uma causa. O Girlcott estimula as mulheres a substiturems produtos por outros saudáveis que terão menor impacto na saúde dos consumidores no longo prazo (GIRLCOT'T, 2011). No Brasil, Cruz, Pires-Jr e Ross (2013) destacam que há diferença de gênero em contextos envolvendo o boicote consumidor, sendo que mulheres daquela amostra tiveram maior percepção de culpa no boicote no caso da Nike do que homens. Neste sentido, são apresentadas $\mathrm{H}_{3} \mathrm{e}$ $\mathrm{H}_{4}$ :

\section{$\mathrm{H}_{3}$ : Mulheres têm maior Percepção de Eficácia do Boicote (PEB) do que homens.}

\section{$\mathrm{H}_{4}$ : Mulheres têm maior Intenção de Boicotar (IB) do que homens.}

O boicote envolve uma complexa relação entre a individualidade do consumidor e suas emoções (Kozinets; Handelman, 1998). Isso demonstra que a intenção de boicotar uma empresa não depende apenas de aspectos econômicos ou sociais; inclui também a relação que o cliente tem com uma marca, empresa ou produto. Segundo Sen, Gürhan-Canli e Morwitz (2001), os consumidores tendem a tomar uma postura de cooperação no boicote, ou seja, participar junto com outros ex-clientes de um movimento de deixar 
de comprar quando a relação de consumo não é forte com um produto, serviço ou marca. Os autores identificaram que a partir do momento que um produto não se adequa às preferências do consumidor, ou quando o consumidor tem acesso a produtos substitutos, a sua participação no boicote tende a ser encarada como menos dolorosa, pois não envolve o custo do boicote, que na percepção do consumidor aumenta quando ele(a) tem poucas possibilidades de se satisfazer com produtos substitutos e diminui quando as possibilidades de escolha por produtos substitutos aumentam (SEM; GÜRHAN-CANLI; MORWITZ, 2001). Ou seja, um consumidor tem maior probabilidade de boicotar um produto se existem possibilidades de escolha por produtos semelhantes.

A relação com um produto, serviço ou marca pode variar de acordo com os desejos do consumidor ou dos atributos esperados por ele (seja em atributos intangíveis quanto à atuação da empresa ou status que o produto pode gerar, quanto atributos tangíveis - características técnicas do bem ou serviço). Uma relação emocional complexa é estabelecida pelo cliente quando este decide boicotar, sendo que os atributos nesta decisão são individuais para cada consumidor (Kozinets; Handelman, 1998). Então, entender o status, por exemplo, que um produto de luxo proporciona ao consumidor como proposta de valor pode ajudar a compreender motivos que embasam a decisão de boicotar ou não um bem de luxo, ou um bem essencial.

Empiricamente, alguns casos evidenciam manifestações de ativistas que não culminaram em boicotes eficientes a produtos de luxo. No caso da Birmânia, pequeno país no sudoeste asiático, que é reconhecido pela exportação para Europa e Reino Unido de teca (um tipo de madeira escassa), o boicote aconteceu em 2007 pelo fato de 50\% da renda das empresas serem convertidas em apoio ao regime militar do país, que foi considerado não democrático e não respeitoso aos direitos humanos. Entretanto, o boicote não foi eficiente e os móveis de jardim na Europa e Reino Unido continuaram a ser construídos com aquele tipo de madeira originária somente daquela região (CARBINET; MARKER, 2007). Talvez a explicação para o boicote não ter sido eficiente tenha sido o tipo de madeira que é durável, esteticamente delineada e produzida a partir de uma perspectiva sustentável, e a rara presença destes três atributos em bens substitutos. $\mathrm{Na}$ mesma direção, o empresário francês Bernard Arnault do grupo LVHM, foi acusado, em 2008 pelos internautas chineses, de apoio o líder religioso Dalai Lama, o que implicaria em uma postura pró Tibet e contra a China. Embora as acusações tenham repercutido internacionalmente para a principal loja que comercializa produtos de luxo no mundo, o que foi verificado foi um aumento de vendas de 10,52\% em comparação ao mesmo período do ano anterior. Ou seja, a tentativa coletiva de mobilização para o boicote pelos internautas chineses não resultou em boicote e não impactou negativamente a LVHM.

Um experimento conduzido por Sen, Gürhan e Canli (2001) evidenciou que a possibilidade de escolha de um produto substituto impacta na decisão de boicote. Com a possibilidade de o consumidor escolher um bem substituto, a decisão de boicotar foi de $82,8 \%$, enquanto na sua ausência a decisão pelo boicote foi de $66,2 \%$. Supõe-se, a partir do conceito de "custo do boicote" que, para produtos de luxo, menor será o impacto nas motivações para o boicote. Logo, para o bem essencial o comportamento será contrário em $\mathrm{PEB}$ e IB, pois existem atributos que são comuns que não estão relacionados ao status que o produto sinaliza. Em relação aos bens de luxo, que possuem características singulares, como a raridade e o status que a compra e o uso traz ao seu consumidor, o custo do boicote pode aumentar.

Tsai (2005) apresenta uma classificação que é utilizada para entender as motivações para a compra de produtos de luxo pelos consumidores. A orientação pessoal diz respeito à auto-realização do consumidor na compra de um bem. Já a orientação social é uma análise que envolve a impressão que o bem poderá causar em terceiros, visto que as compras de bens de luxo, por razões de status, tendem a ser mais públicas que privadas (TRUONG, 2010). Assim, em um modelo de equações estruturais, Truong (2010) verificou se as aspirações extrínsecas do consumidor de produtos de luxo estariam mais relacionadas à visibilidade do produto (status na percepção de terceiros) ou à questão de atributos de qualidade do produto. Para o bem de luxo analisado os consumidores estavam mais interessados no status que o produto poderia gerar ao tê-lo do que especificamente na qualidade daquele bem.

O boicote, ao envolver uma decisão complexa que vai além de atributos tangíveis (como o status ou a falta do status que o produto/serviço/marca gera ao consumidor), pode ser menos efetivo pela possibilidade desta característica estar associada 
ao bem de luxo ou mais efetivo pela ausência deste atributo intangível. O bem de luxo tem como uma das características a raridade (GALHANONE, 2005; BARTH, 2010; HUBERT, 2011), e ao ser considerado no custo do boicote reforça os atributos emocionais do consumidor (TRUONG, 2010; HONG; ZINKHAN, 1995; BAGWELL; BERNHEIN, 1996; MASON, 1998) na complexa decisão de boicote (KOZINETS; HANDELMAN, 1998). Desta maneira, tem-se $\mathrm{H}_{5}$ :

\section{$\mathrm{H}_{5}$ : A Percepção de Eficácia do Boicote (PEB) pelo consumidor será menor quando se tratar de bens de luxo, em comparação aos bens essenciais.}

A Intenção de Boicotar (IB) do consumidor é posterior à reflexão sobre a atuação da empresa em relação às mudanças necessárias (PEB), mas pode incluir características relacionadas à raridade do bem, status que o produto traz ao proprietário, desempenho superior aos produtos ou serviços concorrentes. Neste sentido, o conflito emocional interno do consumidor no boicote (KOZINETS; HANDELMAN, 1998) pode ser acentuado e levar o consumidor a não boicotar um bem de luxo. Assim, tem-se:

$\mathrm{H}_{6}$ : A Intenção de Boicotar (IB) do consumidor será menor quando se tratar de bens de luxo, em comparação aos bens essenciais.

A próxima sessão apresenta o método da pesquisa empírica para testar as seis hipóteses acima.

\section{Método}

Para testar as hipóteses propostas foi delineado um experimento fatorial 2 (RSC: com/sem) x 2 (Gênero: masculino/feminino) x 2 (Tipo de Bem: luxo/ essencial), entre sujeitos, com o objetivo de verificar a influência das variáveis RSC, Gênero e Tipo de Bem nas variáveis PEB e IB. Para cada célula foram considerados 30 consumidores, o que totalizou uma amostra por conveniência de 240 respondentes (estudantes de graduação em Administração em uma universidade privada na cidade do Rio de Janeiro, com idade média de 20 anos). O instrumento de coleta de dados foi um questionário com 20 questões estruturadas, pré-testado com 22 alunos para as suas quatro versões (com RSC/sem RSC; bem de luxo/ bem essencial).

Para a manipulação de RSC e tipo de bem foi criado um vídeo, com cinco minutos de duração, sobre uma empresa fictícia Alfa que oferece computadores para ao mercado varejista. Para o nível "Com RSC" oforam consideradas três dimensões para a atuação da empresa Alfa: (a) preocupação e ação para com o público interno (destacou-se um bom clima organizacional na empresa e o investimento em cursos para funcionários e estagiários), (b) preocupação e ação para com o meio-ambiente (foram apresentadas medidas eco-eficientes de reutilização e economia de água), e (c) preocupação e ação para com a sociedade (a empresa elaborava e gerenciava projetos sociais em comunidades pacificadas na cidade do Rio de Janeiro). Para o nível "Sem RSC"eas três dimensões foram assim consideradas: (a) falta de preocupação e ação para com o público interno (foi demonstrado o descuido dos superiores no trato com os subordinados e um clima organizacional ruim entre os funcionários), (b) falta de preocupação e ação para com o meioambiente (foi evidenciado que a empresa descarta metais pesados incorretamente no meio-ambiente), e (c) falta de preocupação e ação para com a sociedade (foi apontado a utilização de empresas terceirizadas envolvidas em escândalos de contratação de mão-deobra semi-escrava).

Para a variável Tipo de Bem, foi escolhido o produto computador, visto que édum produto de uso generalizado na população estudada. Para o nível "Bem Essencial"efoi apresentado ao respondente um laptop básico em termos de configurações: acesso àsinternet, preço baixo ( $\mathrm{R} \$ 900,00)$, produto sem inovações em estética e design e um peso similar aos laptops comuns (2,5 kg). Não foi apresentado qualquer tipo de diferenciação, o que tornava o produto comum e com concorrentes diretos no mercado. Para o nível "bem de luxo"eo produto apresentado foi um laptop tipo ultrabook, que se caracteriza por ser um produto exclusivo, com as seguintes informações: configurações avançadas de software, preço de aproximadamente $\mathrm{R} \$ 5.000,00$, design arrojado (fino e compacto) e peso de aproximadamente $1 \mathrm{~kg}$, sendo que o produto pode gerar status para o proprietário por também ser considerado pioneiro pelos seus pares.

Tais níveis foram pré-testados com 31 alunos da mesma população. Na checagem de manipulação para RSC foi usada uma escala de diferencial semântico de 7 pontos (1: sem responsabilidade social; 7: com responsabilidade social), assim como na checagem do tipo de bem (1: produto básico/essencial; 7: produto de luxo). O teste $t$ de comparação de médias demonstrou que os níveis da variável RSC foram percebidos como 
com e sem RSC pelos respondentes $(p=0,00)$. O mesmo se deu pela percepção de bem de luxo (laptop ultrabook) e bem essencial (laptop básico). As variáveis dependentes foram Percepção de Eficácia do Boicote (PEB) e Intenção de Boicotar (IB). Para a mensuração de PEB foi usada uma dimensão "make a difference" da escala de Klein, Smith e John (2004), por ser um estudo pioneiro ao discutir as motivações do consumidor para o boicote. Não se verificou em contexto nacional qualquer utilização desta escala, portanto procedeu-se a tradução reversa (inglês-português-inglês), realizada por quatro especialistas em línguas (inglês e português). Os três itens desta dimensão, adaptados, são: 1) deixar de comprar da Alfa é um meio muito eficiente de fazer a empresa mudar suas ações; 2) todo mundo deveria deixar de comprar da Alfa, pois toda contribuição, seja ela qual for, é muito importante; 3) ao boicotar, eu consigo ajudar a fazer a Alfa mudar sua decisão. A variável IB foi medida por um único indicador, numa escala de 7 pontos (1: não pensaria em deixar de comprar; 7: com certeza deixaria de comprar). Os dados foram analisados pela Análise de Variância (ANOVA) usando-se o software SPSS.

\section{Resultados}

Com relação aos pressupostos da ANOVA, o teste de Kolmogorov-Smirnov possibilita a verificação da normalidade da distribuição dos dados, e o Teste de Levene possibilita verificar a homoscedasticidade (igualdade das variâncias) entre os grupos analisados. Tais testes foram realizados para a variável PEB, comprovando os pressupostos para a ANOVA. Como medida de consistência interna da variável PEB, foi utilizado o alpha de Cronbach $(0,603)$. Na Tabela 1 é apresentada a ANOVA em que é considerada a interação simultânea entre RSC, Gênero e Tipo de Bem com a PEB. Os resultados demonstram que não existe interação entre as variáveis. $\mathrm{Na}$ ANOVA sem a interação entre as variáveis independentes, individualmente somente RSC e TB impactam PEB.

Tabela 1 . Efeito de RSC (percepção de Responsabilidade Social Corporativa), TB (Tipo de Bem) e GEN (Gênero) na Percepção de Eficácia do Boicote (PEB).

\begin{tabular}{lcccrrr}
\hline \multicolumn{5}{c}{ Anova de Três Fatores com Interação } \\
\hline & Variável Dependente:Percepção de Eficácia do Boicote (PEB) & & \\
\hline Fonte de Variação & Soma dos Quadrados & GL & Quadrado Médio & F & valor p \\
\hline Modelo Corrigido & $23,640^{a}$ & 7 & 3,377 & 3,638 &, 001 \\
\hline Intercepto &, 002 & 1 &, 002 &, 002 &, 963 \\
\hline RSC & 16,252 & 1 & 16,252 & 17,507 &, 000 \\
\hline TB & 2,612 & 1 & 2,612 & 2,814 &, 095 \\
\hline GEN &, 425 & 1 &, 425 &, 458 &, 499 \\
\hline RSC * TB &, 026 & 1 &, 026 &, 028 &, 867 \\
\hline RSC * GEN & 3,048 & 1 & 3,048 & 3,284 &, 071 \\
\hline TB* GEN & 1,352 & 1 & 1,352 & 1,456 &, 229 \\
\hline RSC * TB* GEN &, 018 & 1 &, 018 &, 020 &, 889 \\
\hline Erro & 213,514 & 230 &, 928 & & \\
\hline
\end{tabular}

a: $\mathrm{R} 2=0,158(\mathrm{R} 2$ ajustado $=0,072)$. RSC $=$ Responsabilidade Social Corporativa; $\mathrm{TB}=$ Tipo de Bem;

GEN = Gênero. 
Não se rejeita $H_{1}$, ou seja, a variável RSC impacta PEB (quanto menor a percepção de RSC do consumidor, maior a sua PEB; $\mathrm{p}<0,05)$. Assim, os resultados evidenciam que a orientação gerencial para RSC por meio de ações e decisões pode influenciar PEB na perspectiva do consumidor, pois o ato de deixar de comprar de uma empresa que não tem orientação gerencial para RSC faz com que os consumidores reflitam sobre o boicote como uma forma de entender que um possível ato poderia mudar o comportamento de uma empresa em relação às suas decisões e ações que carecem de uma visão socialmente responsável.

Em relação ao gênero, a variável PEB não apresentou diferença entre homens e mulheres e, portanto, $\mathrm{H}_{3}$ foi rejeitada. $\mathrm{Na}$ amostra analisada, tanto homens quanto mulheres não apresentaram diferença em entender que ações e decisões das empresas podem ser mudadas a partir de seus atos individuais de boicote, ou seja, não houve diferença na percepção de eficácia do boicote. Assim, não se pode dizer que consumidores do sexo feminino entendem como mais eficaz seu ato de boicote para mudar decisões e ações de uma empresa do que consumidores do sexo masculino (e vice-versa).

Foi observada diferença significativa $(\mathrm{p}<0,1)$ entre bem de luxo e bem essencial na $\mathrm{PEB}, \log$ o $\mathrm{H}_{5}$ não é rejeitada: PEB será menor quando se tratar de bens de luxo, em comparação aos bens essenciais, na amostra analisada. Isto significa que produtos de luxo, que possuem características singulares, como a raridade e o status que a compra e o uso traz ao seu consumidor, o custo do boicote pode aumentar, e a percepção de eficácia do boicote também. Foi o conceito de Custo de Boicote associado às características intangíveis do bem de luxo que fez com que $\mathrm{H}_{5}$ emergisse. Ao supor que este conflito interno do consumidor pudesse ser maior com um bem de luxo, verificou-se a possibilidade da eficácia do boicote ser menor no grupo exposto ao bem de luxo, pois para o consumidor abrir mão de comprar um produto pioneiro e único no mercado, ele teria que questionar seus valores pessoais, os valores e atuação da empresa, os atributos intangíveis e tangíveis de um bem de luxo e, depois, decidir pelo boicote ou pela compra. Como o bem essencial não apresentava tais características que fizessem suscitar no consumidor tal conflito interno, PEB foi menor no bem de luxo, ou seja, pelo fato do conflito ser maior no grupo bem de luxo, foi menor o valor atribuído pelos consumidores no entendimento de que boicotando eles poderiam mudar as decisões e ações da empresa.

Na Tabela 2 é apresentada a ANOVA em que é considerada a interação simultânea entre RSC, Gênero e Tipo de Bem com a IB. Os resultados demonstram que RSC influencia IB, não se rejeitando $\mathrm{H}_{2}$. Assim, RSC impacta tanto PEB quanto IB. Em outras palavras, RSC influencia (i) na reflexão individual do consumidor no que diz respeito à necessidade de refletir sobre uma possível punição para uma empresa como forma da empresa mudar suas ações e (ii) na intenção do consumidor em boicotar uma empresa.

Tabela 2 . Efeito de RSC (percepção de Responsabilidade Social Corporativa), TB (Tipo de Bem) e GEN (Gênero) na Intenção de Boicotar (IB).

\section{Coeficientes da Regressão}

Variável Dependente: Intenção de Boicotar (IB)

\begin{tabular}{c|c|c|c|c|c}
\hline & Coeficientes Não-Padronizados & GL & $\begin{array}{c}\text { Coeficientes } \\
\text { Padronizados }\end{array}$ & $F$ & valor $p$ \\
\hline Modelo & $91,344^{a}$ & 7 & 13,049 & 5,543 &, 000 \\
Corrigido & 5740,582 & 1 & 5740,582 & 2438,590 &, 000 \\
Intercepto & 3,011 & 1 & 3,011 & 1,279 &, 259 \\
GEN & 73,052 & 1 & 73,052 & 31,032 &, 000 \\
RSC & 10,742 & 1 & 10,742 & 4,563 &, 034 \\
TP & 4,497 & 1 & 4,497 & 1,910 &, 168
\end{tabular}




\section{Coeficientes da Regressão}

Variável Dependente: Intenção de Boicotar (IB)

\begin{tabular}{c|c|c|c|c|c}
\hline & Coeficientes Não-Padronizados & GL & $\begin{array}{c}\text { Coeficientes } \\
\text { Padronizados }\end{array}$ & F & valor $p$ \\
\hline Modelo & $91,344^{a}$ & 7 & 13,049 & 5,543 &, 000 \\
Corrigido & 5740,582 & 1 & 5740,582 & 2438,590 &, 000 \\
Intercepto & 1,194 & 1 & 1,194 &, 507 &, 477 \\
GEN * RSC &, 202 & 1 &, 202 &, 086 &, 770 \\
GEN * TP &, 202 & 1 &, 202 &, 086 &, 770 \\
GEN * RSC* & 541,433 & 230 & 2,354 & & \\
TP & 6355,000 & 238 & & & \\
Erro & 632,777 & 237 & & & \\
Total & Total Corrigido & & & & \\
\hline
\end{tabular}

a: $\mathrm{R} 2=0,144(\mathrm{R} 2$ ajustado $=0,118) . \mathrm{RSC}=$ Responsabilidade Social Corporativa; $\mathrm{TB}=$ Tipo de Bem; GEN = Gênero.

Conforme Tabela 2, a variável gênero não teve impacto em IB ( $\mathrm{p}>0,05)$, rejeitando-se $\mathrm{H}_{4}$. Os resultados nesta amostra apresentam empiricamente análises diferentes às de Kalsen (2005), Neilson (2010), Barda e Sardianou (2010) e Stolle, Hogge e Micheletti (2005) e, portanto, não se pode afirmar que mulheres têm maior intenção de boicote do que homens. Verificou-se que a IB do consumidor foi menor para bens de luxo, em comparação aos bens essenciais, $\operatorname{logo} \mathrm{H}_{6}$ não foi rejeitada. As características do produto exercem influência na intenção do consumidor em boicotar: consumidores expostos a um bem de luxo intentam a boicotar menos que consumidores expostos a um bem essencial. Ao agregar em um só produto diversos atributos tangíveis e intangíveis que o torne singular em um determinado mercado, um bem de luxo ou exclusivo pode ser menos vulnerável ao boicote.

\section{Considerações finais}

Este artigo investigou o efeito das variáveis RSC, gênero e tipo de bem na Percepção de Eficácia do Boicote (PEB) e Intenção de Boicotar (IB) do consumidor, em contexto brasileiro.

A não rejeição de $\mathrm{H}_{1}$ e $\mathrm{H}_{2}$ evidencia que responsabilidade social corporativa é uma variável influenciadora tanto para a percepção de eficácia do boicote (PEB) quanto para a intenção de boicotar (IB). Os estudos de Soule (2009), Friedman (1999), Palazzo e Basu (2007) e Smith, Palazzo e Bhattacharya (2010) sugeriam o impacto de RSC no boicote e aqui foi verificado que o consumidor pode achar que vale a pena boicotar a empresa se RSC for um problema. Ou seja, ele(a) pode acreditar que o boicote seja relmaente eficaz para que a empresa mude suas ações de RSC. O respondente viu aqui a ausência de RSC como uma motivação para o seu boicote a uma empresa, sendo esta motivação de fato considerada na sua intenção de parar de comprar (boicotar).

Em relação ao tipo de bem (essencial ou luxo), conclui-se que o consumidor considera atributos intangíveis em sua intenção de boicotar, uma vez que ao associar os conceitos de Custo de Boicote (SEN; GÜRHAN-CANLI; MORWITZ, 2001) e o boicote como decisão conflituosa para o consumidor (KOZINETS; HANDELMANS, 1998) neste estudo verificou-se que um bem de luxo tende a provocar menor intenção de boicotar (IB) e menor percepção de eficácia do do boicote (PEB) que um bem essencial. Assim, é possível que no boicote o consumidor considere em maior grau de importância os atributos tangíveis e intangíveis de um bem de luxo em relação a um bem essencial e que este conjunto de características possa aumentar o conflito interno na intenção de boicote, explicando, assim, porque um bem de luxo tende a ser avaliado diferentemente em 
relação ao boicote, se comparado a um bem essencial. Não se verificou diferença entre homens e mulheres nas variáveis $\mathrm{PEB}$ e IB, uma vez que $\mathrm{H}_{3}$ e $\mathrm{H}_{4}$ foram rejeitadas. Desta maneira, não existem evidências na amostra de que mulheres têm maior intenção de boicotar do que homens ou que a reflexão delas sobre a necessidade de uma empresa mudar suas ações leve-a a ter maior percepção de PEB que os homens.

\section{Implicações, limitações e pesquisa futura}

Uma contribuição deste estudo é que se trata do primeiro trabalho de natureza empírica sobre boicote sob a perspectiva de comportamento do consumidor na literatura de marketing nacional. RSC impactou tanto em PEB quanto em IB, daí a evidência do tema RSC em comportamento do consumidor para o boicote, tanto sob uma perspectiva mais filosófica e ideológica do consumidor (PEB), quanto sob uma perspectiva de conação (intenção para a ação) como componente da atitude do consumidor em deixar de comprar (IB). Tal implicação corrobora as discussões de estudos qualitativos realizados anteriormente (PALAZZO; BASU, 2007; SOULE, 2009) e destaca a importância da orientação gerencial de RSC nas empresas, uma vez que sugere que os consumidores deixariam de comprar produtos de uma empresa que apresente um contexto negativo de RSC. Outro entendimento é que o ato de deixar de comprar é uma estratégia considerada eficaz pelos consumidores no que diz respeito às mudanças que eles esperam de uma empresa que não tem orientação gerencial para RSC. Ou seja, para o consumidor o boicote funciona como uma punição para a empresa para que ela perceba a necessidade de mudança em relação à RSC, o que pode ter significado prático para a área de RSC das empresas.

As abordagens sobre gênero no boicote do consumidor nunca foram aprofundadas (KLEIN; SMITH; JOHN, 2004; BARDA; SARDIANOU, 2010), tratando- o como apenas uma das variáveis demográficas. Embora os resultados do presente experimento não tenham sido estatisticamente significativos com relação a esta variável, insights para futuras pesquisas surgem ao abordar a diferença entre homens e mulheres no boicote, na intenção de boicotar e na percepção da eficácia do boicote. Outras variáveis podem ser mais importantes como moderadoras, como o envolvimento com o produto (que também pode estar associada ao gênero para alguns tipos de produtos).
As características de um produto ou serviço já foram amplamente analisadas na literatura nacional e internacional no que tange à intenção de compra dos consumidores em relação à existência ou ausência de um conjunto de atributos presentes naquele bem ou serviço, no status adquirido pelo proprietário ou pela atribuição de valor por terceiros. Entretanto, poucas abordagens verificaram a existência de impacto do tipo de bem no boicote, sendo uma delas a pesquisa de Sen, Gürhn-Canli e Morwitz (2001), em que se discute o conceito de custo do boicote. Os autores especularam que para bens de luxo o custo do boicote para o consumidor pode ser maior e associam esta informação à questão da inexistência de produtos substitutos no mercado. A verificação de que tipo de bem influencia PEB e IB corrobora o argumento de que o boicote para o consumidor é uma "complexa decisão emocional” (KOZINETS; HANDELMAN'S, 1998). Aqui o tipo de bem influenciou o processo reflexivo do consumidor sobre a necessidade de uma empresa mudar suas ações, e teve influência na intenção do consumidor em deixar de comprar, estando o bem de luxo menos propenso à intenção de boicote do que um bem essencial. A implicação aqui é que quando o consumidor não tem acesso a produtos substitutos (no caso de bens de luxos de maior exclusividade), a sua participação no boicote tende a ser encarada como mais dolorosa, pois envolve o custo do boicote, que na percepção do consumidor aumenta quando ele(a) tem poucas possibilidades de se satisfazer com produtos substitutos e diminui quando as possibilidades de escolha por produtos substitutos aumentam (SEM; GÜRHAN-CANLI; MORWITZ, 2001). Ou seja, um consumidor tem maior probabilidade de boicotar um produto se existem possibilidades de escolha por produtos semelhantes.

O método aqui usado apresenta limitações típicas de um experimento de laboratório, como artificialidade e baixa validade externa, mas também pelo fato de que outras variáveis que não foram aqui analisadas possam influenciar na PEB ou na IB, como o nível de escolaridade (a amostra aqui foi composta apenas de estudanete universitários) e idade. Para a análise do tipo de bem, especificamente o bem de luxo geralmente é um bem exclusivo em um determinado segmento, apresentando menos produtos substitutos. Embora o Ultrabook apresentado pudesse ter um concorrente direto (como o Mac, da marca Apple), em termos de configurações os produtos são diferentes e são específicos para consumidores com perfis diferentes. A variável renda, então, poderia também ser uma 
moderadora nas relações aqui apresentadas, mas que não foi considerada como covariável neste estudo.

O levantamento das informações relacionadas ao boicote de consumidores tanto de conteúdo científico quanto de conteúdo empírico, quando associadas aos resultados deste estudo, possibilita o surgimento de diversas questões que podem ser estudadas por pesquisadores que se interessem pelo tema. Um tema que ainda não teve inserção nos principais periódicos do país, demonstrando sua ampla possibilidade de abordagem tanto numa perspectiva qualitativa ou quantitativa, evidencia quão rico se constitui o campo interdisciplinar de investigação acadêmica no estudo do boicote do consumidor. Isso acontece pela transversalidade do tema, pois os desdobramentos do boicote não impactam somente na área de Marketing e sua sub-área de Comportamento do Consumidor. Embora seja interdisciplinar, a agenda de pesquisa listada abaixo busca ser fiel à área de Marketing e suas respectivas subáreas:

1. A partir da taxonomia apresentada por Friedman (1999), Koku (2011), Cruz e Botelho (2015) e Cruz (2016b) pode-se investigar, por meio de um experimento, qual o tipo de boicote (econômico, ecológico, de minorias, labor boycott, religioso, relacional e experencial) apresentaria maior PEB ou maior IB;

2. As plataformas digitais têm evidenciado que nas RSVs dos consumidores a questão envolvendo política está presente no contexto brasileiro. É possível que o boicote político seja analisado à luz da comportamento do consumidor caso o consumidor deixe de comprar em função de sua ideologia política ou partidária;

3. O caso da Arezzo (boicote ecológico) nas redes sociais virtuais pareceu mais intenso que o caso da Zara (boicote social). Quando apresentado um contexto negativo em relação à responsabilidade social e um contexto negativo em relação à responsabilidade ambiental, em qual dos contextos o boicote do consumidor apresentaria maior impacto na PEB?

4. O custo do boicote como um conflito interno do consumidor esteve presente no argumento teórico para analisar o impacto do tipo de bem nas variáveis de boicote. Este construto carece de análises empíricas, como a construção de um instrumento para a sua mensuração.

Outras questões também podem ser estudadas futuramente, como a influência da categoria de produto (vestuário, tecnologia, alimentos etc.) na intenção de boicotar e o porte da empresa (grande, média ou pequena) como influenciador na força de atos de backlash, ou, especificamente, do boicote. Também, as variáveis Percepção de Eficácia do Boicote (PEB) e Intenção de Boicotar (IB) foram tratadas como dependentes nesta pesquisa, mas pode haver uma relação de interdependência entre elas, ou seja, IB pode ser influenciada por PEB, e isto pode ser investigado em futuras pesquisas. Todas estas questões necessitam de verificação empírica e teórica, e os resultados aqui apresentados podem servir como estímulo a novas investigações científicas sobre boicote, no campo de estudo do Comportamento do Consumidor.

\section{Referências}

AAKER, D. J. Leaveraging the Corporate Brand. California Management Review.Vol. 46, n. 03, p. 6-18, 2004.

BAGWELL, L-S. e BERNHEIM, B. D. Veblen Effects in a Theory of Conspicuous Consumption. The American Economic Review, v. 86, n. 3, 1996, p. 349373.

BARBOSA, L. Consumo Político: Utopia ou Realidade no Brasil? Disponível em: http:/ / colunistas. ig.com.br/consumoepropaganda/2010/11/16/ consumo-politico-utopia-ou-realidade-no-brasil/. Acesso em 12 abr. 2011.

BARDA, C. e SARDIANOU, E. Analysing consumers'activism' in response to rising prices. International Journal of Consumer Studies, 34, p. 133-139, 2010.

BARTH, M. Da necessidade ao desejo: o consumo de luxo e a ascenção do querer. Revista Eletrônica Temática, VI, n. 11, 2010, p. 01-13.

BLOG DA PORTUGUESA. Memória Lusa: o boicote à Parmalat. Disponível em: http:/ / blogdaportuguesa.blogspot.com/2011/05/memorialusa-o-boicote-parmalat.html. Acesso em 05 de jun. 2011.

CARBINET MARKER. Burmese teak sales continue despite boycott. Serial online. Oct 26, 2007, p. 5561:3.

CRUZ, B. de P. A.. Curtir, Comentar, Compartilhar: Redes Sociais Virtuais e TV no Brasil. Curitiba: Editora CRV, 2016a, 210p. 
CRUZ, B. de P. A.. Boicote Experencial. Anais do XIX SemeAd. ISSN 2177-3866. São Paulo: FEAUSP, 2016b.

. O Boicote à Novela 'Salve Jorge':

Evidências do Repúdio do Telespectador Evangélico. Revista Acadêmica Magistro, 1, 13, $2016 c$, p. 17-42.

, PIRES-JR, R. J. M. e ROSS, S. D.. Gender

Difference in the perception of guilt in consumer boycott in Brazil. Gender Differences, Croatia: InTech Publications, 2016.

e ROSS, S. D.. The Buycott Intention Analyzed from Sexual Orientation and Religion: The O Boticário's Brazilian Case. Almanaque Multidisciplinar de Pesquisa, 1, 1, 2016, p. 04-31.

e BOTELHO, D.. Proposition of the relational boycott. Management Research: The Journal of the Iberoamerican Academy of Management, 13, 3, 2015, 315-333.

e ROSS, S. D.. Percepção de Culpa no Boicote de um Bem de Luxo. Revista Pensamento Contemporâneo, 7, 3, 2013, p. 139-155.

. Boicote de Consumidores em Relação à Responsabilidade Social Corporativa. Revista Gestão Social e Ambiental, 7, 1, jan/abr, 2013, p. 19-33.

, PIRES-JR, R. J. M. e ROSS, S. D.. Gender Difference in the perception of guilt in consumer boycott. Revista Brasileira de Gestão de Negócios, 15, 49, 2013, p. 504-523.

DAIRY INDUSTRIES. Bahrain dairy drop Danish identity. April, 2006, p. 11. Disponível em: http://web.ebscohost.com/ehost/pdfviewer/ pdfviewer?sid $=\mathrm{a} 4470653-1 \mathrm{a} 8 \mathrm{a}-4 \mathrm{a} 08-\mathrm{b} 0 \mathrm{~d} 3-\mathrm{e} 49 \mathrm{ab} 4 \mathrm{f} 42$ $924 \% 40$ sessionmgr14\&vid=18\&hid=14. Acesso em 05 jun. 2012.

ENGLE-WARNICK, J. e RUFLLE, B. J. Buyer Countervailing Power versus Monopoly Power: Evidence from Experimental Posted-Offer Markets. Working paper n. 2002-W14, Nuffield College Oxford, 2002.

FRIEDMAN, M. Consumer Boycotts - effecting change trough the marketplace and the media. New York: Routledge, 1999.

G1. Protesto de estudantes em escola de SP vira assunto mais comentado na web. (2011). Disponível em: http://g1.globo.com/jornal-da-globo/ noticia/2011/02/protesto-de-estudantes-em-escolade-sp-vira-assunto-mais-comentado-na-web.html. Acesso em 18 de nov. 2016.

GALHANONE, R. F. O mercado do luxo: aspectos de marketing. Revista Rege-USP, São Paulo, 2005, p. 1-12.

GASTALDO, E. Publicidade e Movimentos Sociais no Brasil: uma reflexão sobre políticas de representação. Revista de Economía Política de las Tecnologias de la Informácion y Comunicación, v. 6, n.1, Ene-Abr, 2004.

GIRLCOTT. The Girlcott Association. Disponível em: http://www.thegirlcott.com/history.shtml. Acesso em 12 nov. 2011.

GOES, T. Boicote evangélico a "Salve Jorge" é marketing de "Rei Davi". Disponível em: http:/ / f5.folha.uol.com.br/colunistas/tonygoes/1174866boicote-evangelico-a-salve-jorge-e-marketing-de-reidavi.shtml. Acesso em 26 mar. 2013.

HONG, J. W. e ZINKHAN, G. M. Self-concept and advertising effectiveness: the influence of congruency, conspicuouness, and response mode. Pshychology \& Marketing, v. 12, n. 1, 1995, p. 38-77.

HUBERT, S. Para além do valor de uso: os valores e significados do consumo de produtos de luxo. Revista Todavia, v.2, n. 2, 2011, p. 71-85.

KALSEN, S. Information Age breeds boycotts by the score. Pittsburgh Post-Gazette. Disponível em: http://web.ebscohost.com/ehost/ detail $?$ vid $=6 \&$ hid $=14 \&$ sid $=0 \mathrm{~b} 45$ adea $-687 \mathrm{f} 2 \mathrm{a} 58 \mathrm{e} 67 \mathrm{c}$ $82 \mathrm{c} 318 \mathrm{ddf} 7 \% 40$ sessionmgr12\&bdata $=$ Jmxhbmc9c HQtYnImc210ZT1laG9zdC1saXZl\#db=nfh\&AN= 2W60052013270. Acesso em 13 nov. 2011.

KLEIN, J. G.; SMITH, N. C. e JOHN, A. Why We Boycott: Consumer Motivations for Boycott Participation. Journal of Marketing, v. 68, p. 92-109, 2004.

KOKU, P. S. On boycotts organized through the internet. Journal of Marketing Development and Competitiveness, v. 5, n. 6, 2011, p. 82-93.

KOZINETS, R. e HANDELMAN, J. Ensouling Consumption: A Netnographic Exploration of The Meaning of Boycotting. Advances in Consumer Research, v. 25,1998 , p. $475-480$.

KREEPS, B. Paixões eternas, ilusões passageiras, Rio 
de Janeiro, Saraiva, 1992.

LANDSBURG, S. E. Price Theory and Applications. Cincinnari: South-Western/Thomson Learning, 2002.

MASON, R. S. The Economics os conspicuous consumption: Theory and Thought Since 1700. Northampton: Edward Elgar, 1998.

MATILLA, A. S., HANKS, L. e KIM, E. E. K.The impactof company type and corporate social responsibility messaging on consumer perceptions. Journal of Financial Services Marketing, v. 15, n. 2, p. 126-135, 2010.

MOURA, R. e MENDES, A. Órgãos de defesa do consumidor lançam campanha de boicote a postos BR. TV União. Disponível em: http:/ / tvuniaodenatal.tv.br/noticia.php?id=1700. Acesso em 11 abr. 2012.

NAN, X. e HEO, K. Consumer Responses to Corporate Social Responsibility (CSR) Iniatives. Journal of Advertising, v. 36, n. 02, p. 63-74, Summer, 2007.

NEILSON, L. Boycott or buycott? Understanding political consumerism. Journal of Consumer Behavior, v. 9, 2010, p. 214-227.

PALAZZO, G. e BASU, K. The Ethical Backlash of Corporate Branding. Journal of Business Ethics, v. 73, p. 333-346, 2007.

e RICHTER, U. CSR Business as Usual?

The Case of the Tobacco Industry. Journal of Business Ethics, v. 33, p. 387-401, 2005.

PYL, B. e HASHIZUME, M. Roupas da Zara são fabricadas com mão-de-obra escrava. Disponível em: http://reporterbrasil.org.br/2011/08/roupasda-zara-sao-fabricadas-com-mao-de-obra-escrava/. Acesso em 26 mar. 2013.

SEN, S., GÜRHAN-CANLI, Z. e MORWITZ, V. "Withholding Consumption: A Social Dilemmaerspective on Consumer Boycotts," Journal of Consumer Research, v. 28 (Dec.), 2001, p. 399417.
SMITH, N. C.; PALAZZO, G.; e

BHATTACHARYA, C. B. Marketing Consequences: Stakeholder Marketing and Supply Chain Corporate Social Responsibility Issues. Business Ethics Quartely, p. 617-641, (Oct - 2010), 2010.

SOARES, c. Arezzo Pelemania e o boicote na internet (Parte 2) - Infográfico. Disponível em: http://www.coisasemanal.com.br/2011/04/ arezzo-pelemania-e-o-boicote-na-internet-parte-2infografico/. Acesso em 26 de mar. 2013.

SOULE, S. A. Contention and Corporate Social Responsibility.Oxford: Cambridge University Press, 2009.

STOLLE, D., HOOGUE, M. e MICHELET'TI, M. Politics in the Supermarket: Political Consumerism as a form of Political Participation. International Political Science Review, v. 26, n. 3, 2005, p. 245-269.

TRUONG, Y. Personal aspirations and the consumption of luxury goods. International Journal of Market Research, v. 52, n. 5, 2010, p. 653-671.

TSAI, S. P. Impact of personal orientation on luxurybrand purchase value. International Journal of Market Research, v. 47, n. 4, 2005, p. 429-545.

VARMAN, R. e BELK, R. W. Nationalism and Ideology in an Anticonsumption Movement. Journal of Consumer Research, v. 36, p. 686-700, 2009. 